Special issue of the 2nd International Conference on Computational and Experimental Science and Engineering (ICCESEN 2015)

\title{
Ballistic Protection Evaluation of Sequencing the Composite Material Sandwich Panels for the Reliable Combination of Armor Layers
}

\author{
I.K. YILMAZCOBAN ${ }^{a, b, *}$ AND S. DONER ${ }^{c}$ \\ ${ }^{a}$ University of California, Berkeley, Mechanical Eng. Dept, Berkeley, CA, USA \\ ${ }^{b}$ Sakarya University, Mechanical Eng. Department, Sakarya, Turkey \\ ${ }^{c}$ Istanbul Technical University, Aeronautics and Astronautics Eng. Dept., Istanbul, Turkey
}

\begin{abstract}
Impact problems are usually interesting for the military, either for defensive or offensive purposes to develop armor or ammunition. Recently, daily applications request safety of the products, therefore, it is essential to understand the material behavior under intense short duration or impact loadings. Metallic armor is extremely heavy and would not be popular for personal protection. However, reinforced fiber composites have been used for these purposes. In present study, carbon-fiber-reinforced aluminum honeycomb, aramid and plywood materials were used for armor matrix layers. For determining the capability of sequencing the composite layers, ballistic tests for all six combination of sequenced sandwich panels for three different composites were evaluated at a speed of $700 \mathrm{~m} / \mathrm{s}$ using a 36 caliber one-cored projectile. To obtain cheaper and reliable solutions for further studies of various test conditions, computer aided ballistic simulations were analyzed. To make sufficient correlations, the test results and the computer simulations were compared to each other. Finally, plywood used between the aramid and the carbon-fiber-reinforced aluminum honeycomb sandwich panel has shown the most accurate and the reliable results of the tests and the computer simulations.
\end{abstract}

DOI: 10.12693 /APhysPolA.130.342

PACS/topics: 45.50.Tn, 46.15.Cc, 81.05.Qk

\section{Introduction}

Generally, impact problems were primarily of concern of the military, either for defensive or offensive purposes to develop armor or ammunition. Nowadays, civilian applications demand extreme safety of the products, therefore, it is essential to understand the material behavior under intense short duration or impact loadings [1,2]. Needless to say, metallic armor is extremely heavy and would not be popular for personal protection. On the other hand, reinforced fiber composites have been used for these purposes, but have been shown to be very susceptible to impact damage, thus limiting their usefulness for such application [3-5].

The ballistic impact event is far from simple to be modeled. Many variables, such as shape and mechanical behavior of the projectile, angle of incidence, and velocity of the impact, just to list a few more commonly studied variables, play an important role in the ballistic performance of a material $[6,7]$.

The protection of military and law enforcement personnel from injury by high-velocity-object impact has created new challenges for fundamental scientific research since World War II and even more so, recently. In particular, impact-energy-absorbing material development and characterization has become an imminent task for the scientific research community. As an important class of shock-absorbing materials, fabrics and flexible fibrous

\footnotetext{
*corresponding author; e-mail: kyilmazcoban@berkeley.edu
}

composites have been widely used in the bullet-proof vests and other body armor systems. Recent use of these materials in personnel protection applications creates an urgent need to develop a better scientific understanding of the mechanical response of these materials and the components made of these materials [8].

The development of lightweight and inexpensive ceramics and armor designs for personnel, vehicle, helicopter and structural applications is under ongoing attention by both ceramic armor manufacturers and armor users. These armor systems consist of advanced ceramics as one of the most important component, which assists to defeat projectiles through the ballistic impact energy dissipation. Usually ceramic armor systems consist of a monolithic ceramic or composite ceramic-metal body, covered by ballistic nylon and bonded with a high tensile strength fiber lining or laminated polyethylene, such as

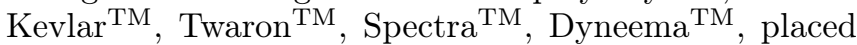
on the back of the ceramic or ceramic-metal composite. Some soft metals (e.g. aluminum thin sheets) may be also used as a backing material. In some cases, a spall shield is attached on the front of armor. Due to higher requirements to ballistic performance in some particular field situations, more complicated armor system designs may be used [9].

Today, police officers in most countries wear different kinds of body armor suitable for different operations. Kevlar is used in the manufacture of both bullet and stabproof armor worn by police/military forces. In bulletproof armor, long strands of fibers form a dense net that absorbs the ballistic energy. Evidently the fibers must be 
able to distribute the whole impact force across the entire vest, ensuring that the impact force is not felt locally and intensely [1].

Both the designers and users of body armor face interesting choices - how best to balance the competing requirements posed by weight, thickness and cost of the armor package for a particular threat level. An armor system made of a single material may be good enough to resist the impact of small caliber ammunition. However a multi-component armor system such as a hard faced ceramic armor with composite backing is necessary and is widely used to defeat armor piercing projectiles. These projectiles have a hard core material, such as hardened steel or tungsten carbide, and the ceramic face helps to blunt and erode the projectile tip during impact. The composite backing absorbs the kinetic energy of the decelerated projectile and also catches the ceramic and projectile fragments preventing them from doing further harm [10].

In this study different types of composite layer combinations were tested under ballistic tests and simulations. For the composite layers, carbon-fiber-reinforced aluminum honeycomb, epoxy reinforced kevlar 49 and plywood were used. Various combinations of composite layers were tested with the long-barreled rifle and the 36 caliber projectile. After the test procedure, computeraided explicit (dynamic) simulations were evaluated for all material combinations.

\section{Materials and methods}

\subsection{Materials}

For the ballistic tests and simulations, three types of composite layer combinations were tested. All materials dimensions were $200 \mathrm{~mm}$ (width) $\times 200 \mathrm{~mm}$ (length). The thicknesses of the specimens were different.

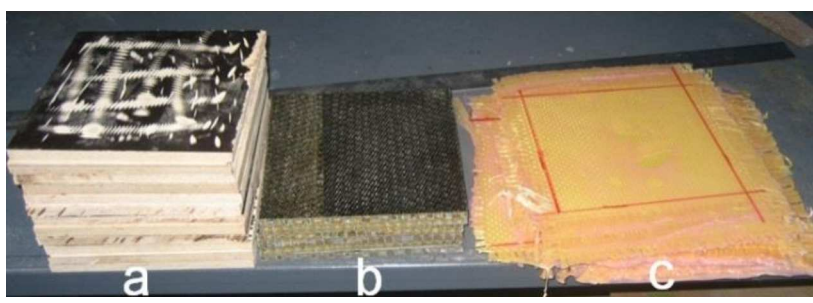

Fig. 1. Composite specimens (a) birch plywood, (b) carbon-fiber-laminated Al5052 honeycomb, (c) epoxyreinforced Kevlar 49.

For the first material, nine-layered plywood with total thickness of $12 \mathrm{~mm}$, made of European birch wood was used. As a second material, three layers of kevlar 49 fabric were used. Kevlar layers were reinforced with epoxy resin (Huntsman Ly 3505). The total thickness of the epoxy-reinforced kevlar layers was $4 \mathrm{~mm}$. For hardening the resin, Huntsman XB3405 hardener was preferred. The density of the used kevlar is $1440 \mathrm{~kg} / \mathrm{m} 3$. The third composite material is carbon-fiber-reinforced aluminum honeycomb. For the aluminum honeycomb, an Al5052 sheet with a thickness of $0.3 \mathrm{~mm}$ was taken. The honeycomb height was $7.2 \mathrm{~mm}$. Laminated carbon fiber with a thickness of $0.9 \mathrm{~mm}$ was used on the bottom and top sides of the aluminum honeycomb. Between the different composite layers Araldite 2021 Epoxy glue was applied. The composite materials can be seen in Fig. 1 .

A matrix is composed when different composite layers come together. For all matrices two plywood layers were used one after another, and viewed as a single plywood layer. Three different composite layer combinations were evaluated. Thus, six different matrix combinations were created using this scenario. The matrix combinations of the composite layers are given in Table I.

TABLE I

Sequence of the composite layers of the studied specimens.

\begin{tabular}{c|c|c|c}
\hline \hline \multirow{2}{*}{$\begin{array}{c}\text { Composite } \\
\text { specimen } \\
\text { combination }\end{array}$} & \multicolumn{3}{|c}{ Sequence of composite layers } \\
\cline { 2 - 4 } & First & Second & Third \\
\hline 1 & Plywood $\times 2$ & Kevlar & Honeycomb \\
2 & Honeycomb & Kevlar & Plywood $\times 2$ \\
3 & Kevlar & Honeycomb & Plywood $\times 2$ \\
4 & Kevlar & Plywood $\times 2$ & Honeycomb \\
5 & Plywood $\times 2$ & Honeycomb & Kevlar \\
6 & Honeycomb & Plywood $\times 2$ & Kevlar
\end{tabular}

\subsection{Ballistic tests}

For the ballistic tests, Safir T14 long-barreled rifle (a different type of shotgun) was preferred. The barrel length of the rifle is $510 \mathrm{~mm}$ and the total length of the rifle is $960 \mathrm{~mm}$. The weight of the rifle is $2850 \mathrm{gr}$. Yavascalar 36 caliber one-cored projectile (Fig. 2) was used in the shots. The weight of the bullet is $7.5 \mathrm{~g}$ and the initial velocity of the projectile when it is fired from the rifle is $700 \mathrm{~m} / \mathrm{s}$.

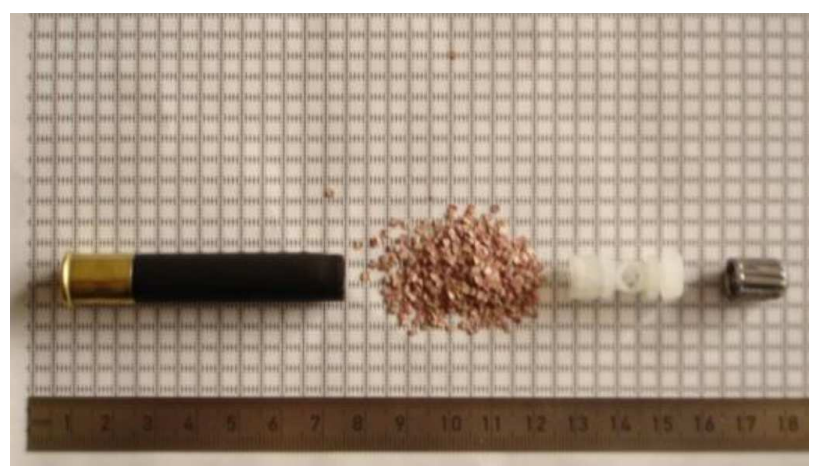

Fig. 2. Yavascalar 36 caliber one-cored projectile.

The test setup was composed of a fixed steel table and a steel frame in which the composite layered matrices could be adjusted by a bolt system (Fig. 3).

Because of the security reasons the distance between the rifle and the target was chosen to be $10 \mathrm{~m}$. However, 


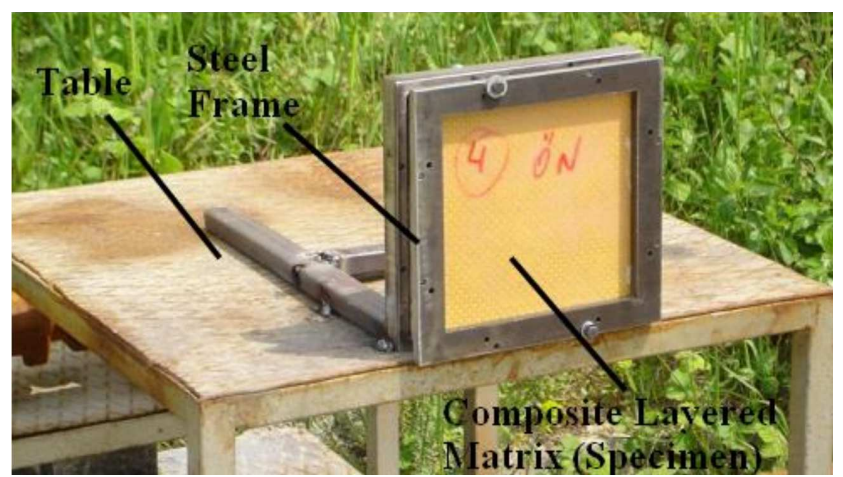

Fig. 3. Ballistic test setup.

for more realistic conditions, the rifle was not fixed but handled by a sniper.

\subsection{Computer simulations}

In order to understand the procedure of the ballistic tests, to reduce the real time test expenses and time, and to make further calculations, computer aided ballistic simulations were evaluated with the help of ANSYSLSDYNA Explicit solver. To reduce the time of the simulations quarter-symmetric finite element models were used (see Fig. 4).

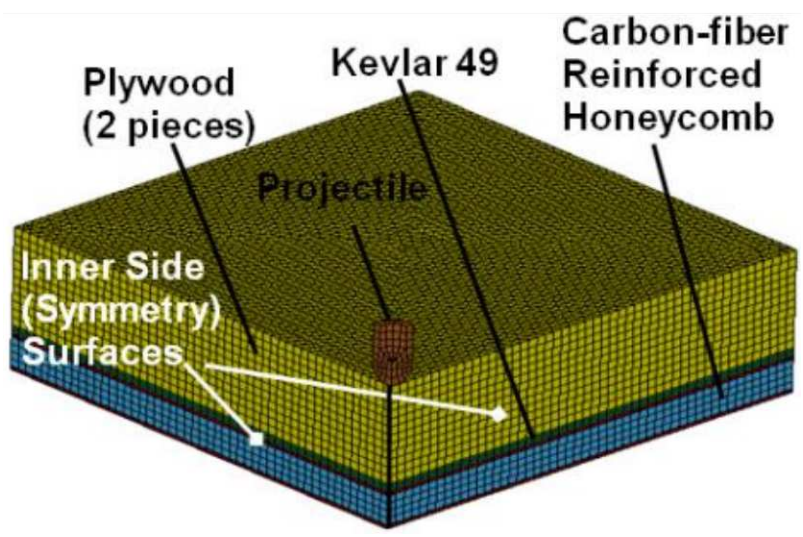

Fig. 4. Quarter FE model of the combination 1.

In the analysis solid elements were chosen for the elements. For the simulation process time value of 0.1 millisecond was applied. Just for determining the results of the composite armors, the projectile was considered as a rigid material. The outer side surfaces of composite layers were fixed in all degrees of freedom. The inner side surfaces were fixed from the normal axis of their surfaces. Like in the test procedure, the initial velocity of $700 \mathrm{~m} / \mathrm{s}$ was assigned to the projectile. Static friction coefficient was 0.2 and the dynamic coefficient was considered to be 0.15 . For the reliable results the finite element models were meshed with sweep technique and hexahedral elements were generated. All of the six composite combinations were modelled under these ballistic conditions with LSDYNA code. Plastic kinematic material model used for the composites.

When the projectile was going through the armors, to get realistic results and to show the broken parts of the layers, failure parameter was used. In these simulations, based on our former trials and practice, failure parameter was accepted as 0.75 . When a finite element reached this percent of its tension value, it was considered broken off from the main part.

\section{Results and discussion}

After the ballistic tests, the composite material sandwich panel combinations were cut into two pieces along the projectile trajectories. The results are shown in Fig. 5. For the first combination, the projectile has pierced the armor. Although the plywood layer delamination was observed, kevlar and honeycomb have stayed together. However the last layer of carbon-fiberreinforced honeycomb was broken. Thus, this combination cannot not protect a person from the rifle attack.
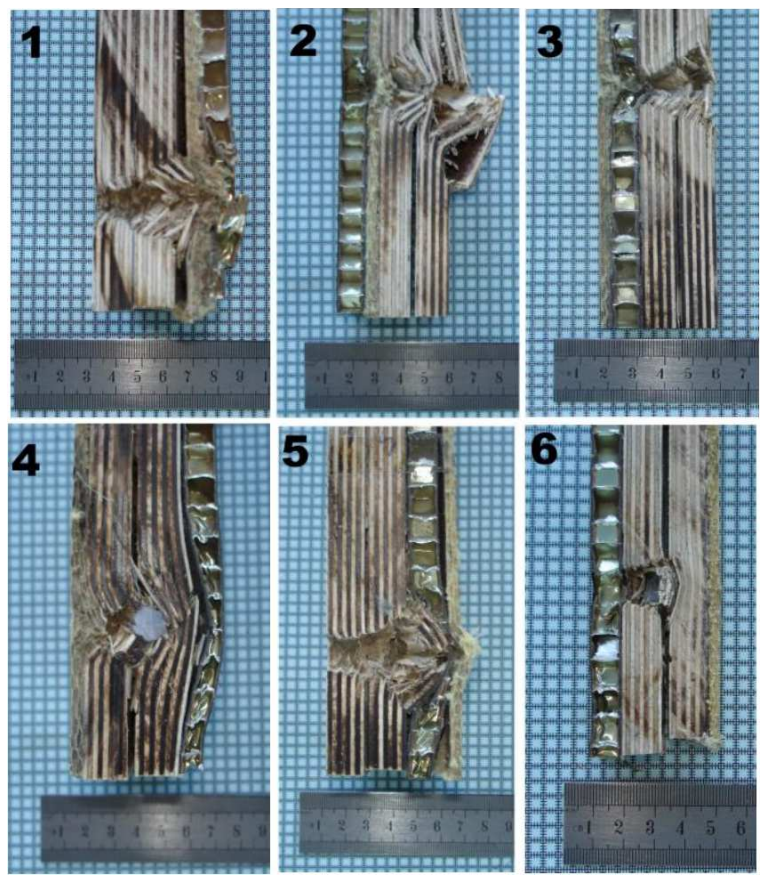

Fig. 5. Ballistic test results of the composite combinations.

When the second sandwich panel combination was investigated, which had the inverted sequencing of the first matrix, the result was not changed. Little delamination occurred between the plywood layers. Plywood as a backing material did not solve the problem. Last plywood layers were broken into parts. And this combination was probably the worst composite sandwich panel.

In the third armor, just the order of the carbon fiber reinforced honeycomb and the epoxy reinforced kevlar layers were changed. The results were the same. No protection was gained. 
When the fourth composite combination was evaluated, a valuable projectile absorbing was observed. After the tough contact with the hard epoxy reinforced kevlar 49, the projectile could not pass through the second plywood layer. The backing material of carbon-fiberreinforced aluminum honeycomb was compressed and absorbed the second plywood layer's energy. Little delamination was found between the plywood layers. However, the personnel protection was achieved.

The fifth combination was made by inverting the third composite sequencing. In this sandwich paneled armor, projectile could not be defeated by the first layer because of not being a hard composite. Thus, the velocity of the projectile was too fast to absorb the energy by the last two consecutive composites.

In the sixth composite combination, projectile was successfully absorbed, as in combination four. This sequencing was the opposite of the fourth one. Here the delamination between the plywood layers was found to be stronger than in the fourth composite. However, the projectile almost could not break into second plywood layer.
In this kind of studies, just absorbing the projectile is not enough for protection. The back face signature (BFS) of the projectile is also important for body protection. Allowed BFS protection limits should not be larger than $44 \mathrm{~mm}$. In our study, the BFS of fourth composite combination was $10 \mathrm{~mm}$ and in the sixth combination the BFS was not observed. Just a $2.5 \mathrm{~mm}$ delamination was observed.

In the LSDYNA results, because of accepting the projectile rigid geometry, some differences were obtained for the fourth and sixth composite combinations. In these combinations, lead projectile has changed its geometry and was stopped by the armors in the tests. But in the LSDYNA simulations, because of the rigidity, the projectiles proceeded a little more than expected. However, for the first, second, third and fifth combinations (projectiles passing through the armors) the simulation results are exactly the same as the tests. In the Fig. 6 and 7, the LSDYNA projectile velocity results are given for the first and the forth composite combinations.

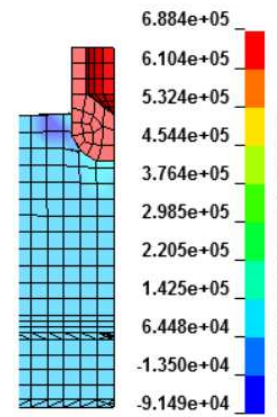

Time 7.99796e-006

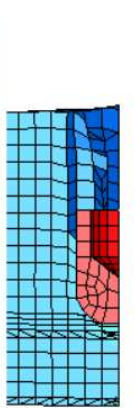

Time $3.79998 \mathrm{e}-005$

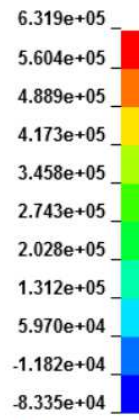

005

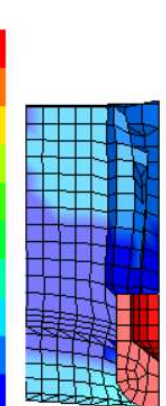

Time $\quad 5.79987 \mathrm{e}-005$

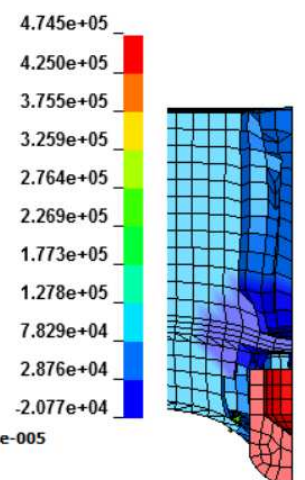

Time

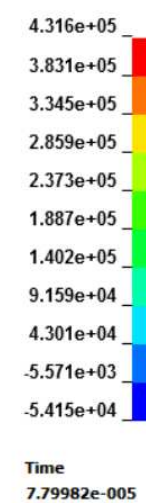

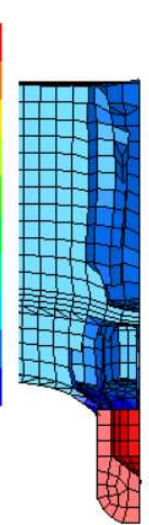

Fig. 6. Velocity results for the first combination of the composite armor.

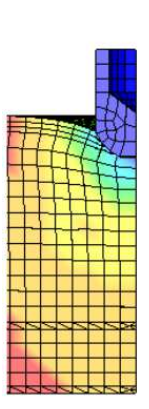

Time $\quad$ 7.99755e-006
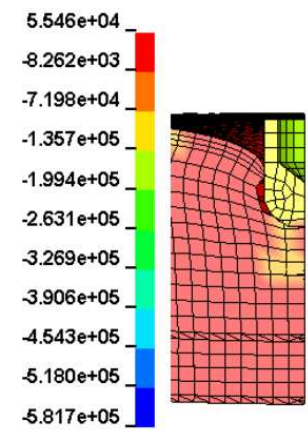

Time $\quad 3.79972 \mathrm{e}-005$
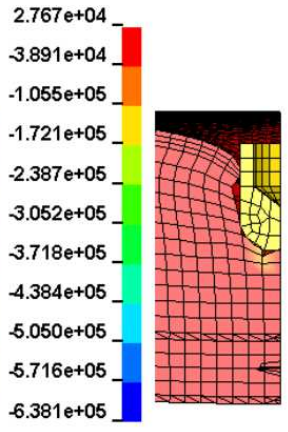

Time $\quad 5.7999 \mathrm{e}-005$
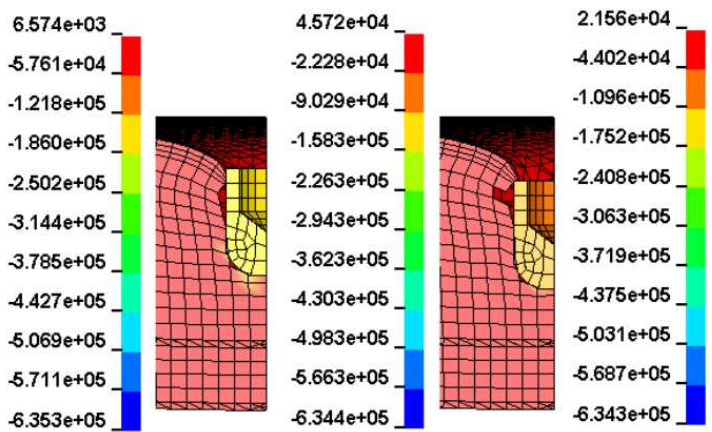

Time $7.7998 \mathrm{e}-005$

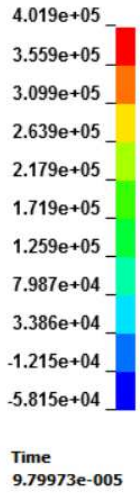

Fig. 7. Velocity results for the fourth combination of the composite armor.

For the first combination (Fig. 6) velocity of the projectile was decreased from $700 \mathrm{~m} / \mathrm{s}$ to $400 \mathrm{~m} / \mathrm{s}$ and the armor has totally deformed as in the tests. For the fourth combination (Fig. 7), the velocity of the projectile was totally absorbed by the composite armor. The results of the fourth composite combination test and the simulation were comparable, the energy of the projectile was absorbed by the armor. 
To understand the protecting ability of the composite materials sandwich panels, the kinetic energy changes of the projectiles for these armors should be considered. To compare the velocity and the energy results, kinetic energy changes, in other words the energy absorbing capabilities of armor, for the first and the fourth combinations are given in Fig. 8.

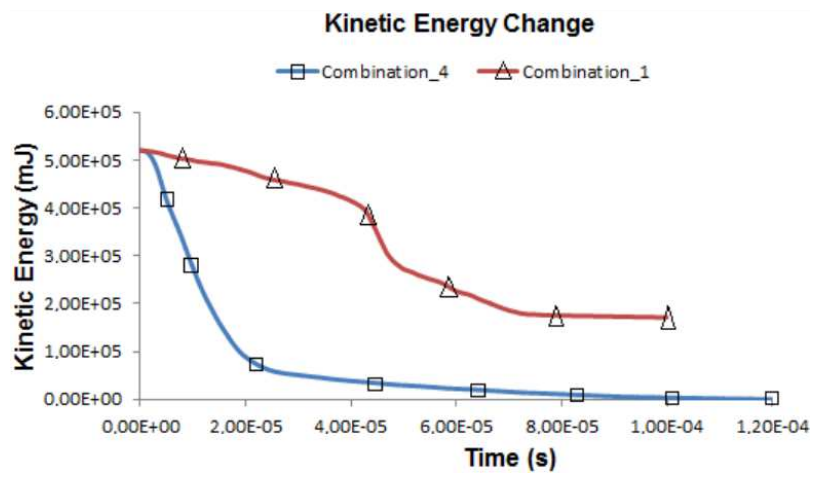

Fig. 8. Kinetic energy changes of the projectile for the combinations 1 and 4.

In the first composite combination after the plywood layer, the kinetic energy absorbing ability was higher, but the kevlar and honeycomb layer were not capable of stopping the projectile. After $0.1 \mathrm{~ms}$, the projectile pierced the armor and continued its way. The energy level of the projectile in the first combination decreased from $520 \mathrm{~J}$ to $171 \mathrm{~J}$. When the fourth combination was considered, initial epoxy-reinforced kevlar 49 layer has absorbed enormous amount of $432 \mathrm{~J}$ of energy. Then less energy of the projectile has ended between the plywood layers.

Based on these results, the projectile must initially contact with a hard material. After having absorbed the initial impact energy of the projectile, second layer should be softer to get the energy of the projectile after a hard impact. The last layers have to support and hold together the hard surface layers and soft layer and to absorb the remaining energy of the projectile. Finally, the LSDYNA simulation results are similar with the tests and thus can be helpful for further studies, for reducing dramatically the cost of the equipment, preparation and test expenses. The correlated results will help to reduce the time and give a chance to make many more different analyses for different material combinations.

\section{Conclusions}

For this study the following results can be concluded:

- Sequencing the material layers is very important.

- Composite layers are reliable enough for a convenient sandwich panel structure, to absorb the energy of a projectile from a rifle.
- The projectile must initially contact with a hard material. After absorption the initial impact energy of the projectile, second layer should be softer to absorb the energy of the projectile after a hard impact. The last layers must hold the middle soft layer together and absorb the remaining energy of the projectile.

- Fourth and the sixth combinations of the composite sandwich panel armors are reliable and safe for a lead, 36 caliber one-cored projectile, fired from a shotgun and having the velocity of $700 \mathrm{~m} / \mathrm{s}$.

- The explicit simulations are correlating with the results of the tests. Finally, it is determined that, the computer aided ballistic simulations were helpful for the studies, by reducing the real-time test expenses and the time and by providing the reliable results.

\section{Acknowledgments}

For this study, we want to thank to the Mech. Eng. Dept. BSE thesis students Abdullah Demir and Murat Emre Öztürk, and also thank to the MSc. thesis student Sefa Emin Ozgultekin from the Sakarya University (2011), who have helped much with the test setup.

\section{References}

[1] D.P. Goncalves, F.C.L. de Melo, A.N. Klein, H.A. AlQureshi, Int. J. Mach. Tools Manuf. 44, 307 (2004).

[2] M.L. Wilkins, Int. J. Eng. Sci. 16, 793 (1978).

[3] M.L. Wilkins, Boron and Refractory Borides, Ed. V.I. Matkovich, Springer, Berlin 1977, p. 633.

[4] M.L. Wilkins, M.W. Guinan, J. Appl. Phys. 44, 1200 (1973).

[5] I.S. Chocron Benloulo, V.A. Sánchez-Gálvez, Int. J. Impact Engng. 21, 461 (1998).

[6] J.E.L. Da Silva Jr, S. Paciornik, J.R.M. d'Almeida, Polymer Testing 23, 599 (2004).

[7] M.A. Meyers, Dynamic Behavior of Materials, Wiley, NJ 1994.

[8] M. Cheng, W. Chen, T. Weerasooriya, Int. J. Solids Struct. 41, 6215 (2004).

[9] E. Medvedovski, Ceram. Int. 36, 2117 (2010).

[10] K. Krishnan, S. Sockalingam, S. Bansal, S.D. Rajan, Composites B 41, 583 (2010). 